\title{
Development of technology of disinfectants based on soda production waste
}

\author{
Elina Salmanova ${ }^{1, *}$, Lyasan Araslanova $^{1}$, Iren $_{\text {Tuktarova }}{ }^{1}$ and Alexey Nazarov ${ }^{1}$ \\ ${ }^{1}$ Ufa state petroleum technological University, Ufa, Russian Federation
}

\begin{abstract}
The main requirements for the development of fundamentally new disinfectants with a high level of efficiency are to reduce toxicity by increasing the technical and economic indicators in the technology of their application. In this paper, an innovative composition of a disinfectant based on iodine monochloride in the complex of waste production of soda and polyvinylpyrrolidone is proposed. The dependence of stability and antibacterial activity of the developed disinfectant is studied. High indicators of stability ( 3 years) and antibacterial activity were obtained on the example of Staphylococcus aureus (S. aureus), Enterococcus fecalis (E. fecalis), Pseudomonas aeruginosa (P. aerginosa), Bacillus subtilus (B. Subtilis No. 12) at the concentration 0.027-0.055, DS versus commercial drug Zhavilar. The antibacterial activity of the disinfectant DS, DS-1 is maintained up to $0.0044-0.0088$ for Pseudomonas aeruginosa, Staphylococcus aureus, Candida albicans and Escherichia coli and exceeds the efficiency of the commercial drug Betadine by $8-28$ times. Thus, the developed formulations are highly effective, while low-toxic and safe for the environment and humans.
\end{abstract}

\section{Introduction}

The development of fundamentally new highly effective disinfectants (DS) is currently an urgent task. Hypothetically, it is proposed to achieve the lowest concentrations of active substances of working DS in the absence of "harmful" load on personnel and the environment [1].

Currently, both in Russia and abroad, there are technologies for obtaining disinfectants based on iodine monochloride (have a wide range of antimicrobial, antiviral and fungicidal effects, and are mainly used in animal husbandry) [2, 3]. Methods for obtaining such drugs have a number of drawbacks (raw materials are highly toxic, unstable). Therefore, the search for new technologies using cheap raw materials (production waste) and low-toxic chemicals with highly effective prolonged action is relevant [4].

\section{Methods}

\subsection{Disinfectant composition based on soda production waste}

The accumulation of significant volumes of solid and liquid waste in many industries is due to the existing level of processing technology of the corresponding raw materials and the lack of its integrated use.
This paper discusses the possible methods of soda production waste recycling on the example of JSC "Bashkir soda company".

The most harmful and voluminous waste of soda ash production by ammonia method is distiller suspension, formed in an amount of $8-10 \mathrm{~m}^{3}$ per 1 ton of soda. This is predetermined by the technology itself, by which it is impossible to achieve full use of raw materials. Distiller suspension is a solution of calcium and sodium chlorides, calcium hydroxide and sulfate. The solid residue of the distiller liquid (calcium carbonate sludge) in dry form is a light gray mass with a density of about $970 \mathrm{~kg} / \mathrm{m}^{3}, 70-80 \%$ consisting of particles with a size of 0.1-0.2 mm. Its composition depends on the quality of raw materials used in soda production, some technological and other factors. In addition to the distiller liquid, the waste products of soda ash production are: basement, brine cleaning slime, waste gases of carbonation columns and column gas washers, air filters and waste gases of calcining and lime furnaces [1, 2-4].

For the analysis of soda production waste, the following samples were taken [6]:

1 - Initial distiller liquid (IDL);

2 - Brine sludge (BS);

3 - Clarified distiller liquid (CDL).

Samples of waste BS, IIDL, CDL, were filtered. Qualitative and quantitative analysis of the solid phase of the samples was carried out by $\mathrm{x}$-ray phase method on

\footnotetext{
* Corresponding author: elipiper@mail.ru
} 
the x-ray diffractometer "D2 PHASER". The main components are $\mathrm{CaCO}_{3}$ and $\mathrm{CaCO}_{4}$.

Table 1. The concentration of soluble substances in the filtrates

\begin{tabular}{|c|c|c|c|c|}
\hline \multirow{2}{*}{ Composition } & \multirow{2}{*}{$\begin{array}{c}\text { Unit of } \\
\text { measure }\end{array}$} & $\begin{array}{c}\text { Initial } \\
\text { distiller } \\
\text { liquid }\end{array}$ & $\begin{array}{c}\text { Clarified } \\
\text { distiller } \\
\text { liquid }\end{array}$ & $\begin{array}{c}\text { Brine } \\
\text { sludge }\end{array}$ \\
\hline $\mathrm{NaCl}$ & $\%$ & 5.8 & 5.15 & 18.6 \\
\hline $\mathrm{CaCl}_{2}$ & $\%$ & 11.1 & 10.7 & - \\
\hline
\end{tabular}

It is known that iodine monochloride is a fairly effective disinfectant with a wide spectrum of action (it has antibacterial, antiviral and antiparasitic activity) [27].

However, JCl solution shows stability only in the presence of concentrated hydrochloric acid (35\%) [2], which is highly toxic and aggressive, and using of such solution requires personal protective equipment $[4,15]$.

It is shown, in the patent [3], $\mathrm{Na}, \mathrm{Ca}, \mathrm{K}$ chlorides are used as JCL stabilizers [8-11].

Taking into account that in the filtrates of soda waste (IDL, CDL, BS) the main components are $\mathrm{CaCl}_{2}$ and $\mathrm{NaCl}$, the content of which, in total, is $17-18 \%$, it was decided to use these wastes as stabilizers of the solution of iodine monochloride. The best option was CDL sode waste.

In addition, as a source of hydrochloric acid - it was proposed to use abgas hydrochloric acid, formed as a byproduct in the production of caustic (JSC "Bashkir Soda Company").

The method for producing DS based on iodine monochloride is as follows: the reactor is loaded with the necessary amount of water, abgas hydrochloric acid, potassium iodide, potassium Iodate and CDL is added to stabilize the solution $[12,13]$.

\subsection{Complex of iodine monochloride, soda waste and polyvinylpyrrolidone}

Another complexing agent-stabilizer $\mathrm{JCl}$ was proposed using of polyvinylpyrrolidone (PVP). It is known that molecular iodine $\left(\mathrm{J}_{2}\right)$ forms with PVP polymer complexes [14], which have disinfectant properties, stability and prolonged antimicrobial action.

Taking into account that $\mathrm{J}_{2}$ and $\mathrm{JCl}$ molecules have similar complexing properties with electron pair donor molecules, it was proposed to investigate the preparation and properties of the iodine monochloride complex (and its composition with abgas hydrochloric acid and soda waste (CDL filtrate) - DS with polyvinylpyrrolidone (PVP).

To obtain The JCL and PVP complex, a solution containing $5 \mathrm{~g}$ of PVP (molecular weight 10000-12000 Dal) and $46 \mathrm{~g}$ of distilled water in a $100 \mathrm{ml}$ flask was prepared with stirring with a magnetic stirrer for 10 minutes [20].

A base solution of $1.7 \%$ DC prepared in accordance with section 1 was diluted with distilled water (in a ratio of $10 \mathrm{ml} \mathrm{DC}+50 \mathrm{ml} \mathrm{H}_{2} \mathrm{O}$ ) to a concentration of $0.28 \%$ $\mathrm{JCl}$.

Several compositions containing $\mathrm{JCl}$ at a concentration of $0.018-0.056 \%$ and PVP, at a concentration of $0.071-0.130 \%$, i.e. exceeding the concentration of PVP by 19-76 times with respect to $\mathrm{JCl}$, were made on the basis of solutions of polyvinylpyrrolidone and iodine monochloride.

Quality indicators of basic compositions of disinfectants were also determined - it was shown that they have high stability and disinfectant activity.

The study of antibacterial activity and stability of the disinfectant was carried out (table. 2,3).

\section{Results and Discussion}

Spectra of DC components with PVP were made on THE SHIMADZU spectrophotometer UV-2700 in the range of 190-700 $\mathrm{nm}$ and are shown in figures 1 . Spectral characteristics of solutions of JCl-PVP complexes are given in table 2 [20].

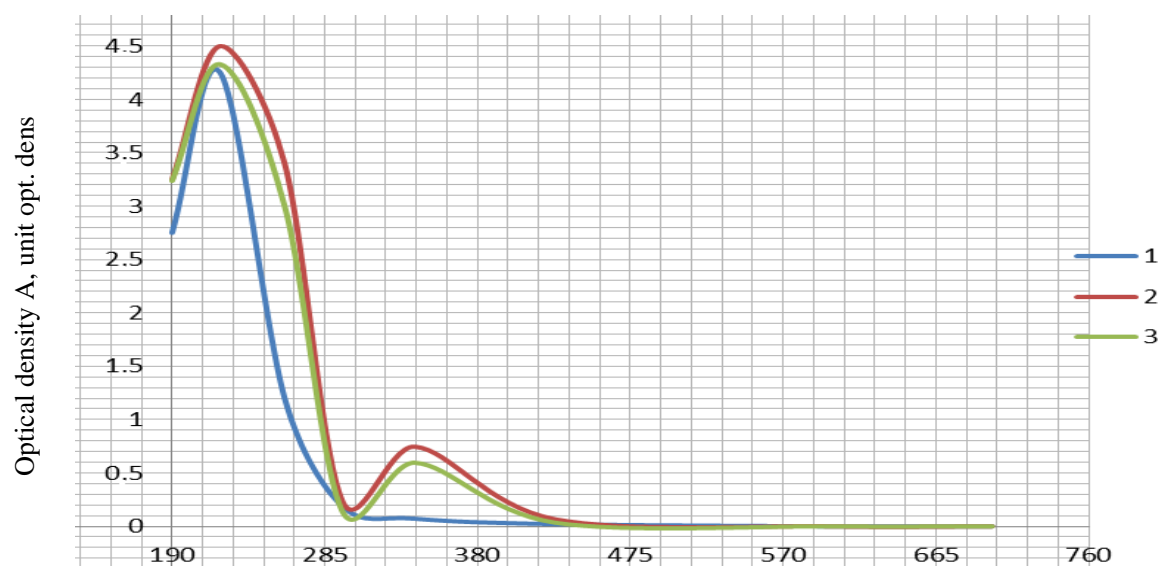

Wavelength $\lambda, \mathrm{nm}$

1 - Spectra of PVP; 2 - Spectra of ICl; 3 - Spectra of JCl+PVP. 
Fig. 1. Spectra of iodine monochloride and polyvinylpyrrolidone complex

Table 2. Spectral characteristics of solutions of JCl-PVP complexes

\begin{tabular}{|c|c|c|c|c|c|c|c|}
\hline \multicolumn{2}{|c|}{ JCl } & \multicolumn{2}{|c|}{ PVP } & \multicolumn{4}{c|}{ Optical density A as a function of wavelength $(\boldsymbol{\lambda})$} \\
\hline $\mathbf{\%}$ & $\mathbf{m o l} / \mathbf{I}$ & $\mathbf{\%}$ & $\mathbf{m o l} / \mathbf{I}$ & $\boldsymbol{\lambda}=\mathbf{2 9 6} \mathbf{~ n m}$ & $\boldsymbol{\lambda}=\mathbf{3 4 1} \mathbf{~} \mathbf{m m}$ & $\boldsymbol{\lambda}=\mathbf{4 2 8} \mathbf{~ n m}$ & $\boldsymbol{\lambda}=\mathbf{3 4 1} \mathbf{~} \mathbf{m}$ \\
\hline 0 & 0 & 9,8 & 0,98 & 0,188 & 0,042 & 0,0 & \\
\hline 0.025 & $1.56^{*} 10-3$ & 0 & 0 & 0.092 & 0.375 & 0.044 & \\
\hline 0.018 & $1.1 * 10-3$ & 0.83 & 0.084 & 0.168 & 0.196 & 0.045 & $0.154 *$ \\
\hline 0.034 & $2.1 * 10-3$ & 0.78 & 0.079 & 0.234 & 0.356 & 0.067 & 0.314 \\
\hline 0.060 & $3.7 * 10-3$ & 0.70 & 0.071 & 0.425 & 0.795 & 0.131 & 0.747 \\
\hline 0.056 & $3.5 * 10-3$ & 1.31 & 0.130 & 0.398 & 0.713 & 0.160 & 0.660 \\
\hline
\end{tabular}

* - optical density at a wavelength of $341 \mathrm{~nm}$ (minus the optical density of pure PVP.

Analyzing the data in the tables and figures it can be noted that with increasing concentration of PVP and the ratio of $\mathrm{PVP} / \mathrm{JCl}$ is the fall in optical density in the region of $341 \mathrm{~nm}$ (i.e. there is a reduction in the concentration of $\mathrm{JCl}$ in unbound form) and a simultaneous increase in optical density in the region 296 and $428 \mathrm{~nm}$, which is a fact indicating the complex formation of PVP with JCl.

It is possible to form a complex complex including the molecule $\mathrm{JCl}\left(\mathrm{NaCl}, \mathrm{CaCl}_{2}\right.$ and $\mathrm{HCl}$, which are part of the DS) and polymer molecules PVP (in case DS-1).

The stability of three samples with an initial concentration of $1.7 \%$ (for iodine monochloride) and for 1 sample with a concentration of $0.17 \%$ (for iodine monochloride) was investigated [4].
The concentration values of the active substance were measured by spectrophotometry according to the optical density [5, 20-22].

By results of researches on 3 samples it is established that stability of a prototype remains $100 \%$ throughout all experimental term of storage ( 111 days at the $\mathrm{t}=45{ }^{\circ} \mathrm{C}$ ) that corresponds to 36 months (3 years) to real term of storage at $20{ }^{\circ} \mathrm{C}$. It was found that the disinfectant remains stable during the storage period-3 years.

It was showed high antibacterial activity (using the cultures - Staphylococcus aureus, Bacillus subtilis, Enterococcus fecalis and Pseudomonas aeruginosa) at the $0.027-0.055 \%$ concentration in relation to hard commercial drug "Zhavilar" based on active chlorine [16-19].

Table 3. The results of determination of antibacterial activity of a prototype of the "DS" in comparison with the sample of "Zhavilar"

\begin{tabular}{|c|c|c|c|c|c|c|c|c|}
\hline \multirow{3}{*}{ Sample } & \multicolumn{8}{|c|}{ Test culture } \\
\hline & \multicolumn{2}{|c|}{ S.aureus } & \multicolumn{2}{|c|}{ E. fecalis } & \multicolumn{2}{|c|}{ P. aerginosa } & \multicolumn{2}{|c|}{ B. subtilis №12 } \\
\hline & Cmin* & $\mathbf{E}^{* *}$ & Cmin & $\mathbf{E}$ & Cmin & $\mathbf{E}$ & Cmin & $\mathbf{E}$ \\
\hline $\begin{array}{c}\text { 1.7-\% experienced a sample } \\
\text { containing IDL }(11.1 \% \\
\left.\mathrm{CaCl}_{2} \text {, and } \mathrm{NaCl}-5.8 \%\right)\end{array}$ & 0.0138 & 1 & 0.11 & 0.5 & 0.055 & 1 & 0.0275 & 1 \\
\hline $\begin{array}{c}\text { The sample containing } 2 \% \\
\mathrm{JCl} \text { and } 18 \% \mathrm{NaCl}\end{array}$ & 0.0275 & 0.5 & 0.055 & 1 & 0.055 & 1 & 0.055 & 0.5 \\
\hline "Zhavilar", $2 \%$ & 0.0138 & 1 & 0.055 & 1 & 0.055 & 1 & 0.0275 & 1 \\
\hline
\end{tabular}

$* \mathrm{C}_{\text {min }}$ - the minimum concentration of the active substance;

$* * \mathrm{E}$ - efficiency with relation to disinfectant "Zhavilar", China (1).

The efficiency of disinfectants was determined as the ratio of the minimum concentrations of DS and DS- 1 to the minimum concentration of the composition sample ("Zhavilar", "Betadin") at which the antibacterial (fungicidal) activity of the drugs is preserved, respectively:

$$
E_{d s}=[\text { Composition sample }] /[D S, D S-1]
$$

The most effective disinfectant composition containing $1.7 \% \mathrm{JCl}$ and distiller liquid waste $(\mathrm{J})$ inhibits the growth of Staphylococcus aureus (S. aerius) suppression is observed up to 128 times dilution (min. concentration 0.0138 ) - not inferior to the comparison drugs - industrial sample of the drug "Zhavilar" (China) - containing active chlorine and surpassing the experimental samples of the comparison drug containing $2 \% \mathrm{JCl}$ and $18 \% \mathrm{NaCl}$ - equal in number to the total concentration of $\mathrm{NaCl}$ and $\mathrm{CaCl}_{2}$ in the waste of IDL.

In order to reduce the activity to inhibit antibacterial growth: Staphylococcus aureus $(0.0138 \%)>$ B. subtilis (min. concentration $0.0275 \%$ ) $>$ Pseudomonas aeruginosa (min. concentration $0.055 \%$ ) $>$ Enterococcus fecal (min. concentration $0.11 \%$ ). It should be noted that the results of tests of antibacterial activity of experimental samples of disinfectant showed their high efficiency [14, 17-18]. 
Table 4. Antibacterial and fungicidal activity of

disinfectants DS and DS-1 with a comparison sample "Betadin".

\begin{tabular}{|c|c|c|c|c|c|c|c|c|c|}
\hline \multirow{3}{*}{$\begin{array}{l}\text { Disinfec- } \\
\text { tant }\end{array}$} & \multirow{3}{*}{$\begin{array}{l}\text { Composi- } \\
\text { tion }\end{array}$} & \multicolumn{8}{|c|}{ The minimum concentration of the active substance, $\%$} \\
\hline & & \multicolumn{2}{|c|}{$\begin{array}{l}\text { Pseudomonas } \\
\text { aeruginosa }\end{array}$} & \multicolumn{2}{|c|}{$\begin{array}{l}\text { Staphylococcus } \\
\text { aureus }\end{array}$} & \multicolumn{2}{|c|}{ Escherichia coli } & \multicolumn{2}{|c|}{$\begin{array}{l}\text { Candida } \\
\text { albicans } \\
\end{array}$} \\
\hline & & Cmin* & $\mathbf{E}^{* *}$ & Cmin & $\mathbf{E}$ & Cmin & $\mathbf{E}$ & Cmin & $\mathbf{E}$ \\
\hline Betadin & $\mathrm{J}_{2}+\mathrm{PVP}$ & 0.25 & 1.0 & 0.0375 & 1 & 0.25 & 1 & 0.25 & 1 \\
\hline DS & $\mathrm{JCl}+\mathrm{CDL}$ & 0.0088 & 28 & 0.0044 & 8.5 & 0.018 & 14 & 0.070 & 3.6 \\
\hline DS-1 & $\begin{array}{c}\mathrm{JCl}+\mathrm{CDL} \\
+\mathrm{PVP}\end{array}$ & 0.011 & 23 & 0.0053 & 7.1 & 0.011 & 23 & 0.042 & 6.0 \\
\hline
\end{tabular}

$\mathrm{C}_{\min }$ - the minimum concentration of the active substance;

E - efficiency with relation to disinfectant "Betadin" (1).

Antimicrobial activity DS and DS-1 in relation to soft commercial drug "Betadin" was show in Table 4. Based on the results summarized in table 4, it can be concluded that in relation to Pseudomonas aeruginosa and Staphylococcus aureus DS shows antibacterial activity up to concentrations of 0.0088 and $0.0044 \%$, respectively, DS-1 showed slightly less activity $(0.011$ and 0.0053 , respectively), but these values are comparable.

In relation to Escherichia coli bacteria and Candida albicans fungi, another picture is observed - in this case, DS-1 has greater antibacterial activity: it showed antibacterial properties at concentrations of 0.011 and 0.042 , and DS at higher concentrations of 0.018 and 0.070 , respectively.

The greatest effectiveness of both disinfectants and the comparison drug showed in relation to Staphylococcus aureus. The activity of disinfectants falls in a row: Staphylococcus Aureus $\rightarrow$ Pseudomonas aeruginosa $\rightarrow$ E. coli $\rightarrow$ thrush mushrooms. So the antibacterial efficiency of DS and DS-1 in relation to the comparison drug "Betadin" is 8.5-28 and 7-23, respectively, and the fungicidal activity is 3.6 and 6 , respectively.

Antibacterial activity of DS disinfectant is maintained up to 32-64 single dilution, 195-390 single for Pseudomonas aeruginosa and Staphylococcus aureus cultures, 4-16 single for Candida albicans and Escherichia coli.

For DS- 1 to 8 times, i.e. $24-96$ (relative to $0.084 \%$ $\mathrm{JCl}$ ), which in terms of the initial concentration of $1.7 \%$ is 160 and $80-160$ times, respectively.

So, the disinfectant showing the greatest antibacterial efficiency against Pseudomonas aeruginosa and Staphylococcus aureus is DS, and in relation to Candida albicans and E. coli DS-1.

\section{Conclusions}

Thus, the production technology a disinfectant based on iodine monochloride, waste soda production (containing of $\mathrm{Na}$ and $\mathrm{Ca}$ chlorides) and PVP was developed. The resulting disinfectants (DS, DS-1) have high stability (3 years) and high antibacterial activity (using the cultures Staphylococcus aureus, Bacillus subtilis, Enterococcus fecalis and Pseudomonas aeruginosa) at the 0.027-0.055
$\%$ concentration in relation to hard commercial drug "Zhavilar" based on active chlorine. The high antimicrobial activity of DS and DS-1 was also revealed in relation to Pseudomonas aeruginosa, Staphylococcus aureus, Escherichia coli, Candida albicans in comparison with the mild commercial drug "Betadine" 8-28 times.

The results obtained in the performance of this work can be recommended for pilot tests and introduction into mass production of disinfectants and detergents for the food industry, medicine, veterinary medicine, medical institutions.

\section{References}

1. N. V. Shestopalov, Actual problems of Disinfectology and tasks to ensure sanitary and epidemiological welfare of the population. Shestopalov N. V. Disinfection case. 94, 4, 10-15 (2015)

2. Veterinary drug, which has a wide spectrum of action iodine monochloride: Pat. 2107502 Grew. Federation: IPC A61K33/18 patent holder of JSC "Veterinary drugs" 6 (1998)

3. E. N. Shcherblyuk, A method for obtaining a solution of hydrochloric iodine monochloride: patent 2278816 ROS. Federation IPK-A61K33/18. Shcherblyuk Ye.N., Voskoboynikova T.S., Asadova N.S.; Patentee (s): JSC "Trinity iodine plant", 5 (2006)

4. S. Krasilnikova, Using of soda production waste. Krasilnikova S., Blinov S. International Multidisciplinary Scientific GeoConference Surveying Geology and Mining Ecology Management, SGEM 16, Energy and Clean Technologies 67-71 (2016)

5. N.A. Bykovsky, Toxicity assessment of the main waste of soda production by phytotesting Key Engineering Materials 769, 166-171 (2018)

6. Krashennikova, S. A. Technology of soda ash and purified sodium bicarbonate: studies. manual for environments. PTU, Rev. and extra M. : Higher. SHK 287 (1985)

7. E.R. Salmanova Creation of innovative technology of detergents and disinfectants on the basis of waste of soda production and oil refining Chemical reagents, reagents and processes of low-tonnage chemistry: materials of the XXX International scientific and technical conference dedicated to the memory of academician of the Academy of Sciences of the Republic 
of Bashkortostan Dilyus Lutfullich Rakhmankulov 232233 (2016)

8. I. A. Baschenko, D. I. Novak, R. N. Churaev, V. E. Kaluzhsky, M. M. Abdeev, K. I. Baschenko, N. L. Egutkin, Disinfectant composition-stabilized solution of iodine monochloride (variants) Patent for invention RUS 2286158 (2004)

9. M. V. Medicine Evaluation of the toxicity and safety of the use of disinfectants Product quality control 7, 11-17 (2018)

10. B. V. Manevich, Development of technological modes of sanitary treatment of dairy equipment with the use of liquid detergents: dis.Cand. tech. Sciences: 05.18.04. Moscow: RSE, 164 - from the collections of the Russian State library (2005)

11. N. Mazumdar, M.L. Chikindas, K. Uhrich, Slow release polymer-iodine tablets for disinfection of untreated surface water Journal of Applied Polymer Science 117, 1, 329-334 (2010)

12. P. V. Olynyk, Features of storage and transportation of medicines in emergency situations. Olynyk P. V. Social aspects of public health 4(44), 15 (2015)

13. A.V. Kashtanov, Investigation of bactericidal and disinfecting activity of the preparation iodine monochloride. Problems of veterinary sanitation, hygiene and ecology: scientific collection. Tr. AllRussian research Institute of veterinary sanitation, hygiene and ecology M., 242-249 (2003)

14. E.R. Salmanova The use of waste soda production to obtain a disinfectant in the collection: waste Management: current state and prospects Collection of articles of the all-Russian scientific and practical conference. Edited by I. O. Tuktarova 232-237 (2018)

15. E.R. Salmanova, The creation of innovative technologies of detergents and disinfectants on the basis of wastes of soda production and refining In the book: chemical reagents, reactants and processes of low tonnage chemistry materials XXX International scientific-technical conference dedicated to the memory of academician of the Academy of Sciences of the Republic of Bashkortostan of Diluca of Lutfulla Rakhmankulov 232-233 (2016)

16. N.V. Seregina, ASSESSMENT OF THE SENSITIVITY OF BACTERIA TO DISINFECTANTS IN A MEDICAL ORGANIZATION In the collection: EUROPEAN RESEARCH collection of articles XVII International scientific and practical conference 132-134 (2018)

17. M. Butko, Classification of disinfectants and evaluation of their effectiveness Russian journal of veterinary sanitation, hygiene and ecology 3(27), 134142 (2018)

18. B. A. Chakchir, G. M. Alekseeva, Photometric methods of analysis: Guidelines. SPb.: SPHFA publishing house 44 (2016)

19. Antiseptic and disinfectants: studies.-method. Manual. Auth.- comp. A 72 A.V. Najarian, N. A. Bizunok, B. V. Dubovik. Minsk: Belarusian state medical University 20 (2004)
20. G. Kampf, Antiseptic stewardship: biocide resistance and clinical implications Antiseptic Stewardship: Biocide Resistance and Clinical Implications 1-694 (2018)

21. A. Kuznetsov Some environmental aspects of the use of disinfectants Disinfection case 89, 3,11-21 (2014)

22. V. Klubin Dependence of electronic absorption spectra of aqueous solutions of iodine monochloride on dilution conditions and storage time. Journal of physical chemistry 91, 4, 620-625 (2017) 